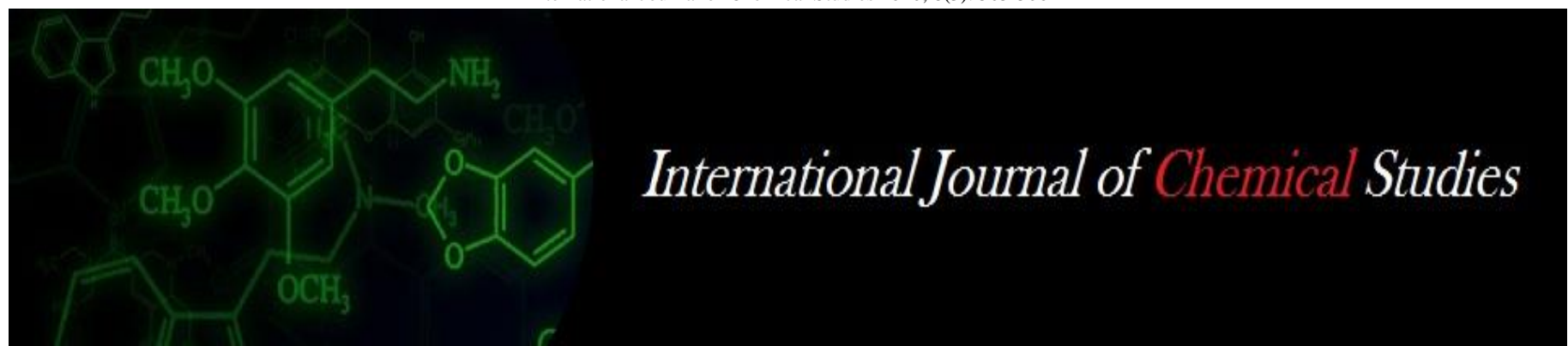

P-ISSN: 2349-8528

E-ISSN: 2321-4902

www.chemijournal.com

IJCS 2020; 8(3): 505-506 (C) 2020 IJCS

Received: 13-03-2020

Accepted: 15-04-2020

Sudeepa Kumari Jha

BAU, Kanke, Ranchi,

Jharkhand, India

Rabindra Prasad

BAU, Kanke, Ranchi,

Jharkhand, India

\section{Relative resistance of aromatic rice against Gundhi bug, Leptocorisa acuta (Thunberg) under agro-climatic condition of Jharkhand}

\section{Sudeepa Kumari Jha and Rabindra Prasad}

DOI: https://doi.org/10.22271/chemi.2020.v8.i3f.9261

\begin{abstract}
The field experiment was conducted to evaluate aromatic rice varieties against gundhi bug, Leptocorisa acuta. The incidence of gundhi bug was recorded highest at the milky stage of the crop. Among thirteen tested aromatic rice varieties BR-9, BR-10, Assam Culture and Badshah Bhog was found relatively more resistance. The population of Gundhi bug reduced when grain become harder.
\end{abstract}

Keywords: Gundhi bug, aromatic rice

\section{Introduction}

Rice gundhi or earhead bug, Leptocorisa acuta (Coreidae: Hemiptera) is one of the serious pests of rice in India and reduce yield by as much as 30 per cent (Tiwari et al., 2014) ${ }^{[1]}$. Both nymphs and adults suck sap from an individual rice grains through mouthpart at milking stage when the starches within the grains are not yet fully formed resulting individual grain became chaffy (Sugimoto and Nugaliyadde 1995) ${ }^{[2]}$. In the process of feeding, rice bugs also contaminate the grain endosperm with microorganisms (Shepard et al., 1995) ${ }^{[4]}$. The site of feeding/ puncturing appeared as black. Morita and Dhanapala (1990) ${ }^{[3]}$ observed that "grain sterility" in rice was actually due to unfilled grains caused by feeding of rice gundhi bug.

\section{Material and Methods}

The field experiments was conducted at Rice Research Farm of BAU, Kanke, Ranchi to screen out total of sixteen rice varieties including one aromatic resistant check i.e. Pusa Basmati-1 and two non-aromatic check i.e. Suraksha (resistant) and TN-1 (susceptible) against gundhi bug, Leptocorisa acuta (Thunberg) during Kharif 2018 and 2019. During both the year of experiment 21 day old seedling were transplanted in three replication on $26^{\text {th }}$ July to main plot with spacing $20 \mathrm{~cm} \times 15 \mathrm{~cm}$ in Randomized Block Design. All the recommended package for cultivation were followed but none of the insecticide were applied in the field either as soil application or seed treatment or foliar application to allow natural population on the insect pests. In each plot ten hills was selected randomly and total number of nymph and adult of Gundhi bug was counted at 80 days after transplanting (DAT) during both the year and their pooled mean was also calculated for computation of experimental finding

\section{Results and Discussion}

The number of GB per ten hills was varied from 12.33 to 36.67 and 10.33 to 31.00 during 2018 and 2019, respectively with lowest incidence was recorded in BR-9 which was at par with PS-5, BR-10 and Suraksha and followed by Assam Culture with 19.33 and 15.00 GB/10 hills during the first and second year of the experiment. Among aromatic test varieties minimum incidence of GB was recorde in Katarani with 28.67 and 25.00 GB/ 10 hills during 2018 and 2019, respectively. In the first year of experiment Katarani was at par with PS-4, Pusa 1176, PS-3, Birsamati, BVS-1, R. Kasturi and R. Subhasani while during the second year of investigation Pusa 1176, BVS-1 and R. Kasturi were significantly superior over Ktarani. The range of pooled mean of number of GB per ten hills among test varieties varied from 11.33 to 33.83 with minimum incidence in BR-9 and it was significantly superior over other test varieties.
Corresponding Author: Sudeepa Kumari Jha BAU, Kanke, Ranchi, Jharkhand, India 
On the basis of pooled mean of two year data the descending order of resistant against gundhi bugs in terms of number of GB per 10 hills was following:BR-9 (11.33) > Suraksha (13.17) > BR-10 (14.50) > PS-5 (15.50) > Assam Culture (17.16) > Badshah Bhog (18.00) > BVS-1 (20.33) > Pusa $1176(20.83)>$ R. Kasturi (21.83) > R. Subhasani (22.00) >
Birsamati (22.33) > PS-3 (23.33) > PS-4 (24.67) > Katarani (26.83) > Pusa Basmati-1 (30.33) > TN-1 (33.83).

Gupta et al. (1993) reported that rice varieties Annada and other up land variety of 105 days duration showed higher damage (3.39 to $6.21 \%$ ) than other up-land varieties of short duration. Ghule (2006) ${ }^{[6]}$ found that none of the varieties was free from incidence of rice earhead bug.

Table 1: Relative incidence of gundhi bug, Leptocorsia acuta (Thunberg) in certain aromatic rice varieties

\begin{tabular}{|c|c|c|c|c|}
\hline \multirow{2}{*}{ Var. } & \multirow{2}{*}{ Rice Varieties } & \multicolumn{3}{|c|}{ No. of GB /10 hill (80 DAT) } \\
\hline & & 2018 & 2019 & Pooled Mean \\
\hline $\mathrm{V}_{1}$ & PS-4 & $27.00(5.29)$ & $22.33(4.83)$ & $24.67(5.07)$ \\
\hline $\mathrm{V}_{2}$ & Pusa 1176 & $22.67(4.86)$ & $19.00(4.46)$ & $20.83(4.67)$ \\
\hline $\mathrm{V}_{3}$ & PS -3 & $24.67(5.06)$ & $22.00(4.77)$ & $23.33(4.92)$ \\
\hline $\mathrm{V}_{4}$ & PS -5 & $17.33(4.26)$ & $13.67(3.83)$ & $15.50(4.05)$ \\
\hline $\mathrm{V}_{5}$ & Birsamati & $24.00(5.00)$ & $20.67(4.65)$ & $22.33(4.83)$ \\
\hline $\mathrm{V}_{6}$ & BVS-1 & $22.67(4.86)$ & $18.00(4.35)$ & $20.33(4.62)$ \\
\hline $\mathrm{V}_{7}$ & BR-9 & $12.33(3.62)$ & $10.33(3.36)$ & $11.33(3.50)$ \\
\hline $\mathrm{V}_{8}$ & BR-10 & $16.00(4.11)$ & $13.00(3.73)$ & $14.50(3.94)$ \\
\hline $\mathrm{V}_{9}$ & Katarani & $28.67(5.44)$ & $25.00(5.10)$ & $26.83(5.28)$ \\
\hline $\mathrm{V}_{10}$ & Badshah Bhog & $20.00(4.57)$ & $16.00(4.11)$ & $18.00(4.36)$ \\
\hline $\mathrm{V}_{11}$ & Assam Culture & $19.33(4.50)$ & $15.00(3.97)$ & $17.16(4.26)$ \\
\hline $\mathrm{V}_{12}$ & R. Kasturi & $24.33(5.02)$ & $19.33(4.50)$ & $21.83(4.78)$ \\
\hline $\mathrm{V}_{13}$ & R. Subhasani & $24.00(4.97)$ & $20.00(4.58)$ & $22.00(4.78)$ \\
\hline $\mathrm{V}_{14}$ & Pusa Basmati-1 (SC) & $33.00(5.83)$ & $27.67(5.35)$ & $30.33(5.60)$ \\
\hline $\mathrm{V}_{15}$ & Suraksha (RC): Non aromatic & $15.67(4.08)$ & $10.67(3.40)$ & $13.17(3.73)$ \\
\hline $\mathrm{V}_{16}$ & TN-1 (SC): Non aromatic & $36.67(6.13)$ & $31.00(5.65)$ & $33.83(5.90)$ \\
\hline & S.Em. $( \pm)$ & $(0.25)$ & $(0.20)$ & $(0.13)$ \\
\hline & $\mathrm{CD}(\mathrm{P}=0.05)$ & $(0.71)$ & $(0.57)$ & $(0.39)$ \\
\hline & C.V. $(\%)$ & $(8.91)$ & $(7.84)$ & $(5.02)$ \\
\hline \multicolumn{5}{|c|}{ Figures in parentheses are square root transformed value } \\
\hline
\end{tabular}

\section{References}

1. Tiwari A, Pandey JP, Tripathi K, Pandey D, Pandey B, Shukla N. Effectiveness of Insecticides and Biopesticides against Gundhi Bug on Rice Crop in District Rewa (M. P.), India. International Journal of Scientific and Research Publications 2014; 4(1):1-4.

2. Sugimoto A, Nugaliyadde. Damage of rice grain caused by the rice bug, Leptocorisa oratorius Fabricus (Hemiptera: Alyidae). JIRCAS Journal. 1995; 2:13-17.

3. Morita H, Dhanapala MP. 'S-called' grain sterility of rice in Sri-Lanka in 1985 yala and 1985-86 Maha cropping season. Japa. J Trop. Agric. 1990; 34:20-26

4. Shepard BM, Barrion AT, Litsinger JA. Rice-feeding insects of Tropical Asia. International Rice Research Institute, Manila, Philippines. 1995, 228.

5. Gupta SP, Prakash A, Rao J, Gupta A. Qualitative losses of paddy grains due to bugs in farmer's fields of costal Orissa. Indian J Ent. 1993; 55(3):29-236.

6. Ghule SD. Seasonal incidence and management of rice earhead bug, Leptocorisa acuta Thinberg (Coreidae: Hemiptera) through varieties and botanical insecticides in South Gujarat. M.Sc. (Agri) Thesis submitted to Navsari Agricultural University, Navasari (Gujarat), 2006. 